\title{
THEORETICAL FOUNDATION OF STRUCTURAL GEOMORPHOLOGY (TO THE 110TH BIRTHDAY ANNIVERSARY OF N.A. FLORENSOV)
}

\author{
D. V. Lopatin ${ }^{1}$, V. P. Chichagov ${ }^{2}$, T. M.Skovitina3 ${ }^{3}$, A. A. Shchetnikov $3,4,5$ \\ ${ }^{1}$ Institute of Earth Sciences of Saint Petersburg State University, Saint Petersburg, Russia \\ 2 Institute of Geography of RAS, Moscow, Russia \\ ${ }^{3}$ Institute of the Earth's Crust, Siberian Branch of RAS, Irkutsk, Russia \\ ${ }^{4}$ Irkutsk Scientific Center, Siberian Branch of RAS, Irkutsk, Russia \\ ${ }^{5}$ A.P. Vinogradov Institute of Geochemistry, Siberian Branch of RAS, Irkutsk, Russia
}

\begin{abstract}
Nikolai Aleksandrovich Florensov is a Russian scientist who is famous for his contribution to the theoretical foundations of structural geomorphology. He formulated the law of the circulation of material in the Earth's crust, which is manifested by a periodically arising lithodynamic flow, in the development cycle of which two main phases are distinguished as ascending and descending geodynamics. In our opinion, there is also the third phase, stabilization. This process is reflected in the morphological types of mountains. Considering the conditions of intracontinental orogeny, N.A. Florensov distinguished two main types: constructive and destructive. Developing this concept, he solved a number of theoretical and philosophical problems concerning the inextricable relationship between the relief and the structure of the geological substratum, its geodynamics and, as a consequence, proposed to consider their relationship as changes in geomorphological formations in time and space. The scientific creativity of NA. Florensov, as a whole, is comparable in importance with that of other most prominent geomorphologists of the late 19th and 20th centuries, including V.M. Davis, W. Penk, S.S. Shults, I.P. Gerasimov, and L. King.
\end{abstract}

Key words: structural geomorphology; lithodynamic flow; intracontinental orogeny; constructive and destructive mountains; geomorphologic formation 


\title{
ТЕОРЕТИЧЕСКИЕ ОСНОВЫ СТРУКТУРНОЙ ГЕОМОРФОЛОГИИ (К 110-ЛЕТИЮ Н.А. ФЛОРЕНСОВА)
}

\author{
Д. В. Лопатин ${ }^{1}$, В. П. Чичагов ${ }^{2}$, Т. М. Сковитина ${ }^{3}$, А. А. Щетников $3,4,5$ \\ ${ }^{1}$ Институт наук о Земле Санкт-Петербургского государственного университета, \\ Санкт-Петербург, Россия \\ ${ }^{2}$ Институт географии РАН, Москва, Россия \\ ${ }^{3}$ Институт земной коры СО РАН, Иркутск, Россия \\ ${ }^{4}$ Иркутский научный центр СО РАН, Иркутск, Россия \\ ${ }^{5}$ Институт геохимии им. А.П. Виноградова СО РАН, Иркутск, Россия
}

\begin{abstract}
Аннотация: Н.А. Флоренсов являлся одним из основоположников развития теоретических основ структурной геоморфологии. Им был открыт закон круговорота вещества земной коры в виде периодически возникающего литодинамического потока, в цикле развития которого наблюдаются две главные фазы - восходящей и нисходящей геодинамики. Авторы статьи выделяют еще и третью фазу - стабилизации. Внешним отображением этого процесса являются морфологические типы гор. В условиях внутриконтинентального орогенеза Н.А. Флоренсов выделял два основных типа: конструктивный и деструктивный. Разрабатывая данную концепцию, Николай Александрович решил ряд теоретико-философских задач о неразрывной связи рельефа со структурой геологического субстрата, его геодинамикой и, как следствие этого, предложил рассматривать их связь как смену геоморфологических формаций во времени и пространстве. Оценивая значение научного творчества Н.А. Флоренсова в целом, авторы статьи считают, что оно соизмеримо с таковым других великих геоморфологов конца XIX - XX вв., таких как В.М. Дэвис, В. Пенк, С.С. Шульц, И.П. Герасимов и Л. Кинг.
\end{abstract}

Ключевые слова: структурная геоморфология; литодинамический поток; внутриконтинентальный орогенез; конструктивные и деструктивные горы; геоморфологическая формация

\section{1. ВВЕДЕНИЕ}

28 января 2019 г. мы будем отмечать 110 лет со дня рождения известного геолога и геоморфолога, члена-корреспондента АН СССР Николая Александровича Флоренсова. Его творческий путь измерен полувеком (с 1936 по 1986 г.), в течение которого им были созданы новые научные направления, разработан целый ряд фундаментальных концепций в области теоретической геоморфологии и неотектоники, опубликовано более 200 научных трудов.

О Николае Александровиче написаны книги, статьи и очерки, затрагивающие разные этапы его жизни; его заслуги как основоположника сейсмогеологии, как лидера сибирской научной школы структурной, региональной и эволюционной геоморфологии, четвертичной геологии, новейшей тектоники и палеогеографии кайнозоя, как настоящего ученого-энциклопедиста [Logachev, 1989, 2003; Lopatin, Tomilov, 2011; u dp.].

Авторы данной статьи относятся к двум поколениям геоморфологов, считающих себя представителями научной школы Н.А. Флоренсова и по- следователями его идей. Если два первых автора являются его современниками и непосредственно учениками, сохранившими в памяти светлый образ Учителя, то двое других знакомы с Н.А. Флоренсовым заочно - по рассказам коллег старшего поколения и по его опубликованным трудам.

\section{2. ОСНОВНЫЕ НАПРАВЛЕНИЯ НАУЧНЫХ ИССЛЕДОВАНИЙ Н.А. ФЛОРЕНСОВА}

Одним из важнейших и эффективнейших научных достижений Н.А. Флоренсова является создание школы структурной, региональной и эволюционной геоморфологии, четвертичной геологии, новейшей тектоники и палеогеографии кайнозоя Центральной Азии. Ее формирование связано с региональными тематическими исследованиями, начатыми в 1949 г. с созданием Института геологии Восточно-Сибирского филиала АН СССР, организатором и первым директором которого стал Н.А. Флоренсов. Позиционировал он себя сторонником активно развивающейся новейшей тектоники [Shults, 1948]. Укрепление и расширение 


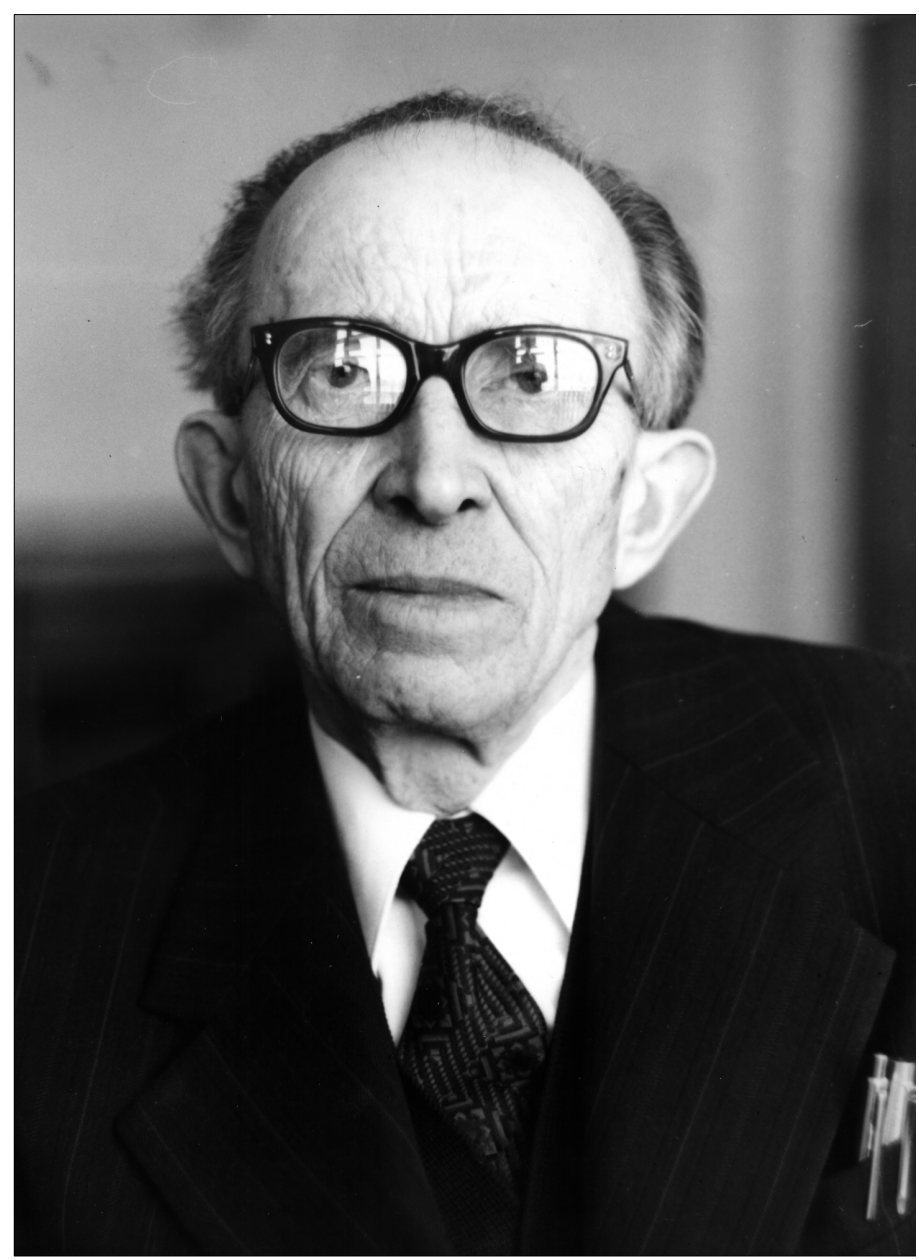

Николай Александрович Флоренсов (1909-1986).

Nikolai Aleksandrovich Florensov (1909-1986).

сферы влияния теоретической геоморфологии в 60-70-е годы XX в. совпало с периодом, когда Николай Александрович заведовал лабораторией тектоники и структурной геологии ИЗК СО АН СССР (1968-1972). С этого времени изучение рельефа земной поверхности, новейшей тектоники и палеогеографии кайнозоя стало одним из основных научных направлений Института земной коры. Кроме того, Н.А. Флоренсов вместе с В.П. Солоненко и коллективом единомышленников, изучив множество прибайкальских, монгольских, среднеазиатских и кавказских землетрясений, смогли создать морфологическую классификацию сейсмодислокаций по силе землетрясений и применили ее в палеосейсмологическом аспекте, что позволило заложить основы нового научного знания - сейсмогеологии [Florensov, Solonenko, 1963; Florensov, Khil'ko, 1976].

В вопросах тектонической предопределенности главных форм рельефа Николай Александрович сумел синтезировать достижения своих предшест- венников - геологов-геоморфологов эволюционистов П.А. Кропоткина, А.Л. Чекановского, И.А. Лопатина, И.Д. Черского, А.В. Львова, В.А. Обручева, братьев Мушкетовых, М.М. Тетяева, С.С. Шульца и многих других. На этой идейной основе и возникла сибирская неотектоническая и геоморфологическая школа Н.А. Флоренсова. Он выдвинул и предложил к обсуждению три фундаментальные взаимосвязанные научные концепции:

- о литодинамическом потоке вещества земной коры;

- о типах и механизмах внутриконтинентального горообразования;

- о геоморфологических формациях.

Значение этих идей можно оценить как выходящее за рамки геоморфологии и представить в качестве мировоззренческого обобщения в науках о Земле. Это обстоятельство позволяет считать Н.А. Флоренсова лидером отечественной и мировой теоретической геоморфологии последней трети XX века.

\section{3. ФУНДАМЕНТАЛЬНЫЕ ПРОБЛЕМЫ ГЕОМОРФОЛОГИИ}

Научное мировоззрение Н.А. Флоренсова постепенно формировалось в процессе решения практических геолого-съемочных, поисковых и управленческих задач. И лишь во второй половине его профессиональной деятельности настало время качественного «скачка» для теоретического осмысления накопленного фактического материала и развития геоморфологических инноваций.

Концепция о литодинамическом потоке вещества земной коры вытекает из признания возможности круговорота ее вещества на разных этапах структурно-вещественных изменений. Она упорядочивает знания о взаимодействии эндодинамических и экзодинамических процессов на поверхности нашей планеты. Н.А. Флоренсов представляет этот процесс как непрерывно-прерывистый. Зарождаясь в недрах Земли в виде тектонических деформаций и выходя на поверхность, вещество литосферы попадает в окислительную среду атмосферы и гидросферы, в результате чего структурные формы подвергаются разрушению. Возникают другие, более сложные, формы рельефа с основными чертами, отображающими свойства разрушающегося субстрата и стиль геодинамики, и во время этого процесса образуются коры выветривания, материал которых под воздействием поля силы тяжести вовлекается в движение вниз по склону. На пути транзита, попадая в разные физико-географические среды, рыхлый поток трансформируется во множество генетических типов, формирующих соответствующий рельеф. 
Авторы статьи считают, что можно выделить еще одну фазу движения вещества. Когда минеральное вещество попадает в так называемые конечные коллекторы, начинается образование осадочных бассейнов, в которых осадки под воздействием давления и тепла претерпевают физикохимическое изменение: литифицируются, метаморфизуются, превращаются в кристаллическую породу и поток прекращает свое движение. Наступает тектоническая пауза, в течение которой возникают условия для формирования поверхностей выравнивания. Следовательно, решая общую задачу деформации литосферы, можно по единству форм рельефа с геологическим субстратом судить о строении и динамике земных недр, прогнозировать вектор движения геологической части материи во времени и пространстве.

Из этого вытекает ряд важнейших аспектов структурной геоморфологии и морфотектоники:

- об унаследованности и наложенности тектонических деформаций;

- о конформности и дисконформности рельефа геолого-структурному плану;

- о времени как о геологическом факторе рельефообразования, где доминантой является не время образования морфологического комплекса или простых форм, а геоморфологический результат независимо от скорости процесса;

- о связи формы и ее геологического содержания.

Все эти вопросы подробно рассмотрены в многочисленных статьях и итоговой монографии Николая Александровича [Florensov, 1978].

Концепция о типах и механизмах внутриконтинентального горообразования явилась следствием анализа так называемой вертикальной фазы литодинамического потока. Рассматривая различия связи морфологии поверхности рельефа и тектонической структуры Внутренней Азии, Н.А. Флоренсов пришел к выводу о том, что, несмотря на определенные черты сходства, необходимо различать четыре кинематических и, соответственно, морфологических типа гор, объединяющиеся в две большие группы - конструктивного и деструктивного рельефообразования.

К группе орогенов конструктивного типа относятся складчатые образования краевых околоплатформенных или межплатформенных горноскладчатых сооружений уральского типа, пьедестальные горы гобийского типа и сибиретипные своды. Горы деструктивного типа представлены системой впадин и хребтов байкальского типа. Рассмотрим это более подробно.

Конструктивные складчатые горы краевых платформенных орогенов отличает складчатая природа тектонических образований с монокли- нальным залеганием горных пород, формирующих куэстовый рельеф. Для них, как и для всех конструктивных гор, характерно отсутствие передового прогиба, взбросо-надвиговый крутой тектонический уступ на границе стыка с жесткими краями платформ. Кроме Уральских гор, к этому типу можно отнести горные хребты Верхоянья, СеттеДабана, Кавказ, Крымские горы, передовой хребет, характерный для Восточного Саяна, и др.

К конструктивным горам гобийского типа Н.А. Флоренсов относил пьедестальные горы, возникшие во время новейшего тектогенеза в условиях тангенциального сжатия в результате начального коробления жесткой коры, последовательного выжимания осевой зоны поднятия и надвигания распадающегося «тела» хребта на обширные подгорные пролювиальные равнины, именуемые «бэлями». Парциальное воздымание гор при этом сопровождается расширением площади хребтов за счет постоянного выжимания все новых и новых краевых пластин, пронизывающих бэли. Подобные структурные формы Николай Александрович предложил называть «форбергами». Формирование предгорных прогибов при таком типе орогенеза не происходит, а «тела» хребтов увеличиваются за счет поднятия на разную высоту пластин, образующих чередование горных гряд и пассивных депрессий между ними. Орогенез сопровождается активным сейсмоморфогенезом. Типичными представителями данного типа гор являются линейные орогены Гобийского и Монгольского Алтая и ТяньШаня.

Конструктивный сибиретипный механизм горообразования связан со сводово-блоковым воздыманием, локализованным в поле сжимающих напряжений. Типичными примерами такого горообразования являются Алтай, Саяны, Хэнтэй, Хангай и др. [Novikov, 2004].

Деструктивный процесс горообразования реализуется в геодинамических условиях тангенциального растяжения земной коры. При этом главную роль играет прогрессирующее впадинообразование, происходящее за счет гравитационного отседания склоновых блоков, и компенсационное поднятие горных хребтов. В отличие от конструктивного механизма гобийского типа, деструктивный объясняет морфотектонику рифтового типа. Типичным примером этого является Байкальская рифтовая зона впадин и хребтов, расположенная вдоль оси внутриконтинентального локального растяжения [Florensov, 1960; Ufimtsev, 1992; Lopatin, Tomilov, 2011; и дp.].

Концепция о механизмах внутриконтинентального горообразования обладает большой информационной емкостью, так как Н.А. Флоренсов привел пример анализа и теоретического осмысления 
явлений новейшей тектоники; при этом главным исследовательским инструментом становится геоморфологическая структура земной поверхности. Данная концепция нашла живой отклик в работах большого количества последователей не только в среде сибирских исследователей. Успех ее дальнейшего развития был предопределен востребованностью подобных фундаментальных разработок для объяснения причин и условий опасных катастрофических процессов, сопутствующих горообразованию и возникновению зон активных разломов в литосфере [Florensov, 1976b].

Концепция геоморфологических формаций базируется на представлении Н.А. Флоренсова о геоморфологической структуре как выражении потенциала статики и динамики земной коры [Florensov, 1976a, 1976b; Lopatin, 1972, 2005]. Он предлагал объединить усилия геологов и геоморфологов в изучении так называемого «геоморфологического слоя», который, по его мнению, включает сам рельеф, энергетику его образования и структуры земной коры. Такой подход способствовал созданию синтезирующего метода познания рельефа земной поверхности, который не отменил при этом аналитических методов, предложенных В. Пенком, И.П. Герасимовым, Ю.А. Мещеряковым, В.П. Философовым и другими геоморфологами. Концепцию геоморфологических формаций можно определить как важное направление в комплексном подходе при изучении взаимосвязи форм земной поверхности с создающими их процессами.

Развивая эти идеи, авторы статьи считают, что первейшей из предпосылок является сопряженное изучение рельефа земной поверхности с морфодинамическим потенциалом геологического субстрата. Реализация такого потенциала осуществляется путем литодинамической препарировки внутренней геологической структуры, которая, в свою очередь, вступает во взаимодействие с окислительной средой атмосферы и гидросферы. Происходит эндодинамическое трансформирование субстрата с образованием горного рельефа, когда литодинамические свойства первого отображаются в геоморфологическом ландшафте в той же мере, что и у новообразующегося эрозионного рельефа.

Под термином «синтезирующий метод познания» Н.А. Флоренсов предложил рассматривать рельеф - субстрат - вертикальные движения как «геоморфологическую формацию», подобно тому, как в геологии различные тектонические режимы прошлого Земли рассматриваются в овеществленном виде геологических формаций. Развивая эту мысль, возможно, было бы правильно сопоставить геоморфологическую формацию с аналогом современной развивающейся геологической формации, а геоморфологический процесс необходимо рассмат- ривать как важную составляющую геодинамического процесса. Таким образом, под термином «геоморфологическая формация» следует понимать морфодинамическое единство рельефа, геологической структуры и геодинамики внешних геосфер. Они имеют весьма определенные картографируемые границы.

Формационный синтез дает возможность изучать воплощение субстрата в тот или иной рельеф со всеми его свойствами и формами структурновещественного содержания. При таком подходе мы в состоянии посредством оценки энергии геодинамики отобразить в количественных параметрах стиль эндодинамического режима конкретных территорий.

\section{4. ЗАКЛЮЧЕНИЕ}

Прослеживая историю развития мировой и отечественной геоморфологической науки, необходимо вспомнить имена тех ученых, которые на разных этапах ее развития определили приоритеты в изучении объекта исследований, в данном случае рельефа земной поверхности. В этом ряду мы хотим выделить шесть столпов геоморфологической науки, отчетливо понимая возможную субъективность. Это ученые трех поколений: В.М. Дэвис (1850-1934), В. Пенк (1888-1923), С.С. Шульц (1898-1981), И.П. Герасимов (1905-1985), Л. Кинг (1907-1989) и Н.А. Флоренсов (1909-1986).

B.М. Дэвис, основываясь на трудах своих предшественников и современников геоморфологовэволюционистов, предложил широко известную универсальную модель развития рельефа горных стран.

В. Пенк представил две исследовательские модели. Первая формулировалась как форма - процесс - структура - скорость деформации земной коры. Вторая имела методологический характер: эндогенные процессы + экзогенные процессы = рельеф + коррелятные отложения, и именно она стала одним из ведущих методологических подходов геоморфологического анализа.

И.П. Герасимов создал учение о геотектурном, морфоструктурном и морфоскульптурном делении земной поверхности. Его многогранная новаторская деятельность широко известна в разных направлениях наук о Земле не только в геоморфологии, но и в почвоведении и физической географии.

С.С. Шульц, основоположник новейшей тектоники, показал ведущую роль геоморфологического анализа в геотектоническом исследовании горных территорий.

Л. Кинг много сделал для решения проблем формирования поверхностей выравнивания на 
обширных платформенных территориях мира и обосновал механизм формирования островных гор.

Н.А. Флоренсов предложил три универсальные взаимосвязанные концепции, рассмотренные выше и основанные на принципе единства рельефа, геологического субстрата и морфодинамики.

Открытия вышеназванных ученых имеют всеобъемлющее научное и мировоззренческое значение.

Авторы считают своим долгом сказать несколько слов о замечательных книгах, при прочтении которых можно почерпнуть многое из научной, творческой, геологической жизни незаурядного ученого, российского интеллигента и просто талантливого человека во всех его проявлениях. Первая книга - сборник воспоминаний о Николае Александровиче - написана его коллегами и близкими родственниками [Logachev, 2003]. Вторая серия очерков под авторством самого Н.А. Флоренсова, в которую вошли как научные, философские и литературные размышления, так и автобиографические записи, оставленные детям и внукам [Florensov, 2009]. Никто из авторов статьи, к сожалению, не участвовал в написании первой книги, поэтому хочется привести здесь несколько воспоминаний, например, первое знакомство с его геоморфологическими трудами...

В фондах Читинского геологического управления до сих пор хранится отчет, написанный Н.А. Флоренсовым в послевоенные годы. В отчете изложены удивительно интересные мысли о возможных перестройках речной сети на правобережье реки Верхняя Ингода в результате проявления дифференцированных движений земной коры. Несмотря на давность этих материалов, они актуальны и востребованы и в наши дни.

Вышедшая в свет в 1960 г. монография Н.А. Флоренсова «Мезозойские и кайнозойские впадины Прибайкалья» вызвала невероятно большой инте- рес у геоморфологов Советского Союза. Например, в журнале «Известия АН СССР, серия географическая» в 1961 г. С.С. Коржуевым, Д.А. Тимофеевым и В.П. Чичаговым была опубликована развернутая рецензия на эту книгу, за которую авторы удостоились благодарности от Н.А. Флоренсова. И спустя 60 лет эта книга по-прежнему остается настольной для геологов-геоморфологов, работающих в Прибайкалье и Забайкалье.

Вспоминается также деятельность Н.А. Флоренсова по составлению и редактированию известного тома трудов ССМГЭ АН СССР и АН МНР «Геоморфология Монгольской Народной Республики» [Florensov, Korzhuev, 1982] и опубликованной в ней впервые картосхемы поверхностей выравнивания территории Монголии, выполненной в соавторстве с С.Д. Хилько, и многое другое.

Несомненно, что Н.А. Флоренсов был ярким, самобытным и многогранным ученым, высокообразованным и интеллигентным человеком, большим знатоком отечественной и зарубежной литературы, как научной, так и художественной. Читая и перечитывая его фундаментальную монографию «Очерки структурной геоморфологии» [Florensov, 1978], снова и снова обнаруживаем если не скрытые, то завуалированные ссылки на известные труды. В частности, не случайно в ней рядом с именем В.М. Дэвиса стоит А. Пенк, а не В. Пенк, как это принято в подавляющем большинстве работ. Безусловно, Николай Александрович Флоренсов продолжает учить нас бережно относиться к научному наследию! Действительно, разве нынче ссылаются, например, на Ога, Кобера и Хиллса...

Николай Александрович знал и мог написать гораздо больше, чем отразил в упомянутой монографии! Но совершенно ясно, что углубленное изучение его трудов еще преподнесет нам новые сюрпризы.

\section{5. ЛИTEPATУPA / REFERENCES}

Florensov N.A., 1960. Mesozoic and Cenozoic Basins of the Baikal Region. Publishing House of the USSR Acad. Sci, Moscow-Leningrad, 258 p. (in Russian) [Флоренсов H.A. Мезозойские и кайнозойские впадины Прибайкалья. М.-Л.: Изд-во АН СССР, 1960. 258 с.].

Florensov N.A., 1976a. Geomorphological formations. In: N.A. Florensov (Ed.), Problems of endogenous relief formation. Nauka, Moscow, p. 399-419 (in Russian) [Флоренсов Н.А. Геоморфологические формации // Проблемы эндогенного рельефообразования / Ред. Н.А. Флоренсов. М.: Наука, 1976. С. 399-419].

Florensov N.A. (Ed.), 1976b. Problems of Endogenous Relief Formation. Nauka, Moscow, 452 p. (in Russian) [Проблемы эндогенного рельефообразования / Ред. Н.А. Флоренсов. М.: Наука, 1976. 452 с.].

Florensov N.A., 1978. Essays on Structural Geomorphology. Nauka, Moscow, 238 p. (in Russian) [Флоренсов Н.А. Очерки структурной геоморфологии. М.: Наука, 1978. 238 с.].

Florensov N.A., 2009. Paths of My Memory. IEC SB RAS, Irkutsk, 215 p. (in Russian) [Флоренсов Н.А. Тропы моей памяти. Иркутск: ИЗК СО РАН, 2009. 215 с.].

Florensov N.A., Khil'ko S.D., 1976. Relief and seismicity In: N.A. Florensov (Ed.), Problems of endogenous relief formation. Nauka, Moscow, p. 259-279 (in Russian) [Флоренсов Н.А., Хилько С.Д. Рельеф и сейсмичность // Проблемы эндогенного рельефообразования / Ред. Н.А. Флоренсов. М.: Наука, 1976. С. 259-279]. 
Florensov N.A., Korzhuev S.S. (Eds.), 1982. Geomorphology of the Mongolian People's Republic. Nauka, Moscow, 259 p. (in Russian) [Геоморфология Монгольской Народной Республики / Ред. Н.А. Флоренсов, С.С. Коржуев. М.: Наука, 1982. 259 с.].

Florensov N.A., Solonenko V.P. (Eds.), 1963. The Gobi-Altai Earthquake. Publishing House of the USSR Acad. Sci., Moscow, 1963. 392 p. (in Russian) [Гоби-Алтайское землетрясение / Ред. Н.А. Флоренсов, В.П. Солоненко. М.: Изд-во АН СССР, 1963. 392 с.].

Logachev N.A., 1989. Nikolai Aleksandrovich Florensov (1909-1986). In: Florensov N.A. Relief and neotectonics. Selected papers. Moscow, p. 3-19 (in Russian) [Логачев Н.А. Николай Александрович Флоренсов (1909-1986) // Флоренсов Н.А. Рельеф и неотектоника. Избранные труды. М., 1989. С. 3-19].

Logachev N.A. (Ed.), 2003. Nikolai Aleksandrovich Florensov: Book of Recollections. Publishing House of SB RAS, Novosibirsk, 170 p. (in Russian) [Николай Александрович Флоренсов: Сборник воспоминаний / Ред. Н.А. Логачев. Новосибирск: Изд-во СО РАН, 2003. 170 с.].

Lopatin D.V., 1972. Geomorphology of the Eastern Part of the Baikal Rift Zone. Nauka, Novosibirsk, 112 p. (in Russian) [Лопатин Д.В. Геоморфология восточной части Байкальской рифтовой зоны. Новосибирск: Наука, 1972. 112 c.].

Lopatin D.V., 2005. The concept of geomorphological formations and ways of its development. Geomorfologiya (Geomorphology) (3), 10-23 (in Russian) [Лопатин Д.В. Концепция геоморфологических формаций и пути ее развития // Геоморфология. 2005. № 3. С. 10-23].

Lopatin D.V., Tomilov B.V., 2011. Irkutsk Scientific Schools of Geology, Geomorphology, Paleogeography and Geodynamics of the Cenozoic. NIKA, St. Petersburg, 144 p. (in Russian) [Лопатин Д.В., Томилов Б.В. Иркутские научные школы геологии, геоморфологии, палеогеографии и геодинамики кайнозоя. СПб.: НИКА, 2011. 144 с.].

Novikov I.S., 2004. Morphotectonics of Altai. Publishing House of SB RAS, Geo Branch, Novosibirsk, 313 p. (in Russian) [Новиков И.С. Морфотектоника Алтая. Новосибирск: Изд-во СО РАН, филиал «Гео», 2004. 313 с.].

Shults S.S., 1948. Analysis of the Modern Tectonics and Relief of the Tien Shan. Notes of the All-Union Geographical Society, New Series, vol. 3. Geografgiz, Moscow, 222 p. (in Russian) [Шульц С.C. Анализ новейшей тектоники и рельеф Тянь-Шаня. Записки Всесоюзного географического общества. Новая серия. Т. 3. М.: Географгиз, 1948. 222 c.].

Ufimtsev G.F., 1992. Morphotectonics of the Baikal Rift Zone. Nauka, Novosibirsk, 216 p. (in Russian) [Уфимцев Г.Ф. Морфотектоника Байкальской рифтовой зоны. Новосибирск: Наука, 1992. 216 с.].

\section{Дмитрий Валентинович Лопатин}

канд. геогр. наук, доцент

Институт наук о Земле Санкт-Петербургского государственного университета

199178, Санкт-Петербург, ул. 10-я Линия Васильевского Острова,

33-35, Россия

e-mail: lopatin@yandex.ru

(iD) https://orcid.org/0000-0003-4869-8703

\section{Валерий Павлович Чичагов}

докт. геогр. наук, г.н.с.

Институт географии РАН

109017, Москва, Старомонетный пер., 29, Россия

e-mail: ochichag@mtu-net.ru

Татьяна Михайловна Сковитина

канд. геол.-мин. наук, с.н.с.

Институт земной коры СО РАН

664033, Иркутск, ул. Лермонтова, 128, Россия

凶e-mail: skovit@crust.irk.ru

\section{Dmitriy V. Lopatin}

Candidate of Geography, Assistant Professor

Institute of Earth Sciences of Saint Petersburg State University 33-35 10-Line of Vasilievsky Island, Saint Petersburg 199178, Russia

Valeriy P. Chichagov

Doctor of Geography, Chief Researcher

Institute of Geography of RAS

29 Staromonetniy pereulok, Moscow 119017, Russia

\section{Tatiana M. Skovitina}

Candidate of Geology and Mineralogy, Senior Researcher

Institute of the Earth's Crust, Siberian Branch of RAS

128 Lermontov street, Irkutsk 664033, Russia 
D.V. Lopatin et al.: Theoretical foundation of structural geomorphology...

\section{Александр Александрович Щетников}

канд. геол.-мин. наук, с.н.с.

Институт земной коры СО РАН

664033, Иркутск, ул. Лермонтова, 128, Россия

Иркутский научный центр СО РАН

664033, Иркутск, ул. Лермонтова, 134, Россия

Институт геохимии им. А.П. Виноградова СО РАН

664033, Иркутск, ул. Фаворского, 1А, Россия

e-mail: shch@crust.irk.ru

(iD) https://orcid.org/0000-0002-4591-6421

\section{Aleksander A. Shchetnikov}

Candidate of Geology and Mineralogy, Senior Researcher

Institute of the Earth's Crust, Siberian Branch of RAS

128 Lermontov street, Irkutsk 664033, Russia

Irkutsk Scientific Center, Siberian Branch of RAS

134 Lermontov street, Irkutsk 664033, Russia

A.P. Vinogradov Institute of Geochemistry, Siberian Branch of RAS

1A Favorsky street, Irkutsk 664033, Russia 